\title{
Seminal Antioxidant Capacity to Oxidative Stress Induced by Electromagnetic Waves Emitting from Cellular Phones on Sperm Quality: An in Vitro Simulation Model
}

\author{
Eugene Baah ${ }^{1,2}$, Christian Obirikorang1, Richard Harry Asmah ${ }^{3}$, Emmanuel Acheampong1, \\ Enoch Odame Anto ${ }^{1,4}$, Michael Bright Yakass ${ }^{5}$, Dickson Mawusi6*
}

\footnotetext{
${ }^{1}$ Department of Molecular Medicine, School of Medical Science, Kwame Nkrumah University of Science and Technology (KNUST), Kumasi, Ghana

${ }^{2}$ Jubail Specialist Hospital, Sakumono, Tema Metropolis, Ghana

${ }^{3}$ Department of Medical Laboratory, School of Allied Health Sciences, College of Health Sciences, University of Ghana, Accra, Ghana

${ }^{4}$ School of Medical and Health Science, Edith Cowan University, Joondalup, Australia

${ }^{5}$ West African Centre for Cell Biology of Infectious Pathogens (WACCBIP), Department of Biochemistry, Cell and Molecular Biology, University of Ghana, Accra, Ghana

${ }^{6}$ School of Basic and Biomedical Sciences, Department of Biomedical Sciences, University of Health and Allied Sciences, Ho, Ghana Email: *mdickson@uhas.edu.gh
}

\begin{abstract}
How to cite this paper: Baah, E., Obirikorang, C., Asmah, R.H., Acheampong, E., Anto, E.O., Yakass, M.B. and Mawusi, D. (2019) Seminal Antioxidant Capacity to Oxidative Stress Induced by Electromagnetic Waves Emitting from Cellular Phones on Sperm Quality: An in Vitro Simulation Model. Advances in Reproductive Sciences, 7, 94-105.
\end{abstract}

https://doi.org/10.4236/arsci.2019.74011

Received: September 6, 2019

Accepted: October 13, 2019

Published: October 16, 2019

Copyright $\odot 2019$ by author(s) and Scientific Research Publishing Inc. This work is licensed under the Creative Commons Attribution International License (CC BY 4.0).

http://creativecommons.org/licenses/by/4.0/ (c) (i) Open Access

\begin{abstract}
With the increasing use of electronic gadgets, the effects of electromagnetic waves on sperm quality have been reported. This study evaluated the capacity of seminal antioxidants to protect spermatozoa from the effects of exposure to non-ionizing cellular phone radiation on markers of semen quality and DNA integrity in an in-vitro model. A total of seventy-three (73) patients attending a fertility centre in Sakumono, Tema metropolis were recruited for this study. About $2-3 \mathrm{mls}$ of freshly ejaculated semen was neatly collected by masturbation with consent and analysed according to the 2010 WHO standard semen analysis. A portion of Semen was exposed to non-ionizing cellular phone radiation for three (3) hours. Superoxide dismutase (SOD) activity levels and DNA fragmentation index (DFI) were determined before and after exposure. Data was entered and analysed using SPSS version 20.00 and Graph pad prism. DFI was positively associated with immobility $(\mathrm{r}=0.233 ; \mathrm{p}=0.05)$ and negatively associated with percentage progressive motility $(\mathrm{r}=-0.258 ; \mathrm{p}$ $=0.028)$, percentage total motility $(\mathrm{r}=-0.233 ; \mathrm{p}=0.05)$ and SOD levels $(\mathrm{r}=$ $-0.270 ; p=0.028)$. There was a significant positive linear relationship between SOD and progressive motility $(r=0.451 ; \mathrm{p}<0.0001)$, vitality $(\mathrm{r}=0.725$;
\end{abstract}


$\mathrm{p}<0.0001)$ and total motility $(\mathrm{r}=0.705, \mathrm{p}=0.05)$. Higher seminal SOD level is protective against the damaging effects of electromagnetic waves on sperm quality.

\section{Keywords}

DNA Fragmentation Index, Superoxide Dismutase, Semen, Non-Ionizing Radiations, Cellular Phones

\section{Introduction}

Generally one in ten couples experience primary or secondary infertility during their reproductive years with majority of the affected residing in the developing world [1] [2]. In developing countries, where childbearing is usually considered as social capital, it is often the female partner that is blamed for any difficulty in conception. However male factor infertility is increasing globally and accounts for about a third of all infertility cases [3] [4].

Oxidative stress generated by free radicals in semen is a major source of DNA fragmentation, which varies from man to man. The two main antioxidant enzymes in semen, superoxide dismutase (SOD) and catalase modulate the rate and effects of oxidative stress on spermatozoa [5]. High levels of mitochondrial superoxide dismutase have been reported to protect cultured cell lines against ionising and or non-ionising electromagnetic radiation-induced oxidative stress [6].

The frequency of electromagnetic fields determines the field energy. For example, X-rays have high frequencies and are capable of causing DNA damage due to their high-energy capacity. In the lower frequencies on the electromagnetic field spectrum are the non-ionising fraction, which includes those emitted from microwaves, television, radio frequencies and cellular phones [7].

In the last decade, the use of mobile telecommunication services and devices in developing countries especially in Africa is on the ascendancy with some individuals having on them as many as four (4) cell phones at any given time. About half of these people currently use multifunctional cellular phones with high electromagnetic frequencies but most are unaware of its health implications [8] [9]. The negative effects of prolonged cell phone usage on human health have been described severally [10] [11] [12].

With regards to male infertility, Agarwal et al. (2008) [13] have reported detrimental effects on the motility and viability of spermatozoa depending on how long men used and kept cell phones in their pockets.

The aim of this study was to assess the capacity of antioxidants in semen to protect sperms from oxidative stress induced by cellular phone electromagnetic waves using sperm parameters and DNA fragmentation index as the measured outcomes. 


\section{Methods}

\subsection{Ethical Consideration}

Ethical Clearance was obtained from the Committee on Human Research, Publication and Ethics (CHRPE) of the School of Medical Sciences (SMS), Kwame Nkrumah University of Science and Technology (KNUST). Written consent was obtained from all participants.

\subsection{Subjects}

Seventy-three (73) men reporting at the fertility centre of Jubail Specialist Hospital in Tema, Ghana for semen analysis were recruited for this study. All recruited men were between 18 - 50 years and had no history of sexually transmitted infection, diabetes, drug addiction and hormonal imbalances that may affect spermatogenesis. Recruited men presented with normal semen analysis per WHO standards [14] (World Health Organisation, 2010). The patient selection was done at a fertility centre (Jubail Specialist Hospital) for men who were coming for semen analysis aging between 18 - 50 years whose semen analysis results were normal per the WHO standards for semen analysis. These patients were given a questionnaire to give their bio data, health and life style history. The selected ones (inclusion criteria) were non-alcoholics, non-smokers, not hypertensive as well as non-diabetics based on the information that were given on the questionnaire.

\subsection{Anthropometric and Demographic Assessment}

Weight in $\mathrm{kg}$ and height in meters were recorded and body mass index (BMI$\mathrm{kg} / \mathrm{m}^{2}$ ) was calculated. A structured questionnaire was administered to record information about participants' residence proximity to telecom mast, the type (analog or smart), number of mobile phones used and the approximate duration per day that their phones are kept in their pants pockets. Information on marital status, occupation, alcohol intake, and cigarette smoking were recorded.

\subsection{Semen Sample Collection}

Participants were given clear written and oral instructions concerning semen collection. Samples were collected by masturbation after 2 - 4 days of sexual abstinence [14] (World Health Organisation, 2010). Participants ejaculated into clean pre-weighed, non-toxic, wide-mouthed sterile plastic semen containers (Shivani Scientific Industries Pvt. Ltd, Mumbai, India) and presented to the resident embryologist(s) within ten minutes after production.

\section{Processing and Treatment}

Samples were allowed to liquefy completely for 15 - 30 minutes at room temperature. Following liquefaction, we performed semen analysis, assayed DNA fragmentation and SOD levels and divided samples into two aliquots: exposed group (exposed to cell phone radiation) and control group (no exposure to cell phone). 


\subsection{Exposure of Semen Samples to Electromagnetic Waves}

The exposed aliquot was exposed to radio frequency electromagnetic waves (RFEMW) emitted from a cellular telephone in standby mode and cellular data services turned on. The measured frequency was $947.6 \mathrm{MHz}$ with average receiving and transmitting powers of $24.78(\mu \mathrm{W})$ and $21.74(\mu \mathrm{W})$ respectively. The SAR for both receiving and transmitting were also $3.29(\mathrm{~W} / \mathrm{Kg})$ and $2.89(\mathrm{~W} / \mathrm{Kg})$ respectively. The distance between the phone antenna and specimen was kept at $2.5 \mathrm{~cm}$ with duration of exposure being 180 minutes in a $35^{\circ} \mathrm{C}$ incubator. The most common telephony frequency used in the study site is $850-950 \mathrm{MHz}$, which influenced our choice of radio frequency used in this study. The unexposed (control) aliquots were also kept in a $35^{\circ} \mathrm{C}$ incubator for 180 minutes but without RF-EMW exposure.

Power density was monitored in control condition (unexposed group) and experimental condition (exposed group) throughout the experiment using a power meter (Anritsu Power Sensor, model MA 24126A, Anritsu Corporation, Kanagawa Japan) at the Ghana Atomic Energy Physics Laboratory. Power density in the 3.2 control condition was 0.01 to $0.1 \mu \mathrm{W} / \mathrm{cm}^{2}$. Power density in the experimental condition was 1 to $40 \mu \mathrm{W} / \mathrm{cm}^{2}$.

\subsection{Frequency and Temperature}

The frequency emitted by the cell phone was confirmed to be $947.6 \mathrm{MHz}$ with a radio frequency spectrum analyser (Kaltman Creations LLC, Georgia, USA). Both aliquots were kept at $35^{\circ} \mathrm{C}$ to mimic the normal reactions in the human body taking into consideration the effect of temperature on ROS formation and semen parameters as baseline analysis on all samples were measured.

\subsection{Pre and Post-Exposure Analysis}

The following assays were performed before and after RF-EMW exposure following similar protocols.

\subsection{SOD Activity Measurement}

SOD levels were assayed by colorimetric method using SOD assay kit (Cayman Chemicals, Michigan, USA) and ELISA plate reader URIT-660 (URIT Medical Electronic Group Co. Ltd., Guilin, China) The seminal plasma (SP) were obtained from each of the aliquot samples from the neat, unexposed and exposed sample (A, A1, A2) after centrifugation with the temperature-regulated centrifuge (Shivani Scientific Pvt. Ltd., India) at $1500 \mathrm{rpm}$ for $10 \mathrm{mins}$ at $4^{\circ} \mathrm{C}$. The SP of each sample were carefully separated and stored at $-80^{\circ} \mathrm{C}$, which is stable for at least one month according to the manufacturer. The supernatant fluid was then diluted by a factor of 30 with sample buffer, and $10 \mu \mathrm{l}$ of the diluted solution used to measure SOD levels (Cu/Zn-SOD (SOD1), Mn-SOD (SOD2) and extra cellular-SOD (SOD3)) per sample as described by the manufacturer (Cayman Chemicals, Michigan, USA). 


\subsection{Semen Analysis}

Immediately after 180 minutes of incubation, both aliquots (unexposed and exposed) were analysed for sperm total motility (progressive and non-progressive motility) and viability according to the 2010 WHO guidelines on semen analysis.

\subsection{DNA Damage/Fragmentation}

Sperm DNA fragmentation was evaluated using the sperm chromatin dispersion assay (SCDA) kit (Sperm Processor, Maharashtra, INDIA). Briefly, aliquots of semen samples were adjusted to concentrations ranging between 5 to 10 million/ml. Fifty microliters of the suspensions were mixed with $1 \%$ low-melting-point aqueous agarose (to obtain a $0.7 \%$ final agarose concentration) at $37^{\circ} \mathrm{C}$. Aliquots of $50 \mu \mathrm{l}$ of the mixture were pipetted onto a glass slide pre-coated with $0.65 \%$ standard agarose dried at $80^{\circ} \mathrm{C}$, covered with a coverslip, and left to solidify at $4^{\circ} \mathrm{C}$ for 4 minutes. The coverslips were then carefully removed, and the slides were immediately immersed horizontally in a tray of commercially prepared denaturation solution $(0.08 \mathrm{~N} \mathrm{HCl})$ for 8 minutes at room temperature in the dark, which generates restricted single-stranded DNA (ssDNA) motifs from DNA breaks. Denaturation was stopped, and proteins denatured by transferring the slides to a tray with neutralizing and lysing solution $(0.4 \mathrm{~mol} / \mathrm{l}$ Tris, $0.8 \mathrm{~mol} / \mathrm{l}$ DTT, $1 \% \mathrm{SDS}$, and $50 \mathrm{mmol} / \mathrm{l} \mathrm{EDTA}, \mathrm{pH}$ 7.5) for 15 minutes at room temperature. The slides were thoroughly washed in Tris-borate-EDTA buffer $(0.09 \mathrm{~mol} / \mathrm{l}$ Tris-borate and $0.002 \mathrm{~mol} / \mathrm{l}$ EDTA, $\mathrm{pH}$ 7.5) for 2 minutes, dehydrated in sequential $70 \%, 90 \%$, and $100 \%$ ethanol baths ( 2 minutes each). The fixed smears were then stained using the Wright staining technique for light microscopy. Results of the SCDA test were expressed as percentage DNA fragmentation (\% DFI).

\subsection{Data Analysis}

Data obtained was cleaned and analysed using Statistical Program for Social Science (SPSS) version 20.0 and Graph pad prism version 7.0. Data was summarized as frequencies, percentages, means and standard deviations. Student t-test and ANOVA were used to compare the significance of the study parameters on continuous scale within and between groups. The effects of the independent variables on the dependent variable were assessed using generalized linear correlations analysis. All tests were two tails and a p-value less than 0.05 was interpreted as significant.

\section{Results}

Socio-Demographic and Anthropometric Characteristics of the Participants

Socio-demographic characteristics and anthropometry of the participants were recorded. A total of seventy-three participants were enrolled. A higher proportion of participants $(78.08 \%)$ had one (1) phone and none of them (100\%) resided close to a telecom mast (Table 1).

The demographics have already been shown in Table 1. 
Table 1. Socio-demographics characteristics anthropometrics of the participants.

\begin{tabular}{|c|c|c|}
\hline Variable & Frequency & Percentage (\%) \\
\hline Age (years) $($ Mean \pm SD) & $38.81 \pm 5.87$ & \\
\hline \multicolumn{3}{|l|}{ Age Groups (years) } \\
\hline $25-30$ & 5 & $6.85 \%$ \\
\hline $31-35$ & 16 & $21.92 \%$ \\
\hline $36-40$ & 21 & $28.77 \%$ \\
\hline $41-45$ & 15 & $20.55 \%$ \\
\hline $46-50$ & 16 & $21.92 \%$ \\
\hline Height $(m)($ Mean $\pm S D)$ & $1.72 \pm 0.048$ & \\
\hline Weight $(\mathrm{Kg})($ Mean \pm SD) & $76.70 \pm 25.91$ & \\
\hline BMI $\left(\mathrm{kg} / \mathrm{m}^{2}\right)($ Mean \pm SD $)$ & $25.91 \pm 2.42$ & \\
\hline \multicolumn{3}{|l|}{ Educational Level } \\
\hline Primary & 2 & $2.74 \%$ \\
\hline Secondary & 8 & $10.96 \%$ \\
\hline Tertiary & 63 & $86.30 \%$ \\
\hline \multicolumn{3}{|l|}{ Marital Status } \\
\hline Married & 73 & $100 \%$ \\
\hline Single & & \\
\hline
\end{tabular}

\section{Proximity of Telecom Mast (50 meters radius)}

Yes

$\begin{array}{lll}\text { No } & 73 & 100 \%\end{array}$

\begin{tabular}{ccc} 
No & 73 & $100 \%$ \\
\hline Type of Phone & & \\
Analog & 2 & $2.74 \%$ \\
Smart & 71 & $97.26 \%$ \\
\hline
\end{tabular}

Keeping Phones in Front, Pockets of Pants

$\begin{array}{ll}\text { No } & 12 \\ \text { Yes } & 61\end{array}$

No. of Phones in Pockets

$\begin{array}{lcc}1 & 57 & 78.08 \% \\ 2 & 13 & 17.81 \% \\ 3 & 3 & 4.11 \%\end{array}$

No. of Days of Abstinence

(Mean $\pm \mathrm{SD}$ )

$3.06 \pm 0.24$

$\mathrm{SD}=$ Standard Deviation, $\mathrm{BMI}=$ Body Mass Index . 
There is a negative correlation between $\mathrm{pH}$ and the DFI before RF-EMW exposure though not significant. SOD levels showed a significant positive correlation with total motility whiles DFI showed a significant negative correlation with total motility across the various interventions or treatments-in the neat, RF-EMW exposed and incubation without exposure. SOD was significantly negatively correlated with DFI in all three arms of sample treatment (Table 2).

There was a consistent significant reduction across treatment arms in the or$\operatorname{der} \mathrm{A}>\mathrm{B}>\mathrm{C}$ for levels of SOD, percentage total motility and vitality of spermatozoa whiles DFI increased across treatment arms in the order $\mathrm{A}<\mathrm{B}<\mathrm{C}$ (Figure 1).

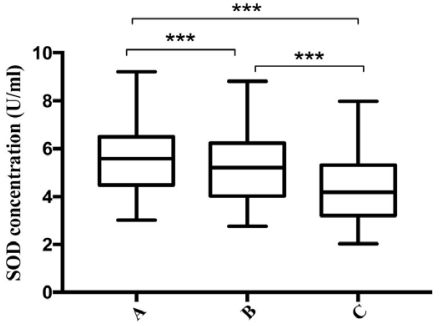

(a)

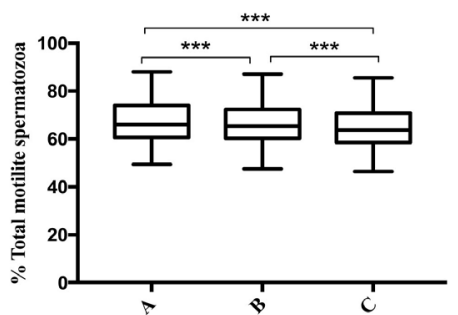

(c)

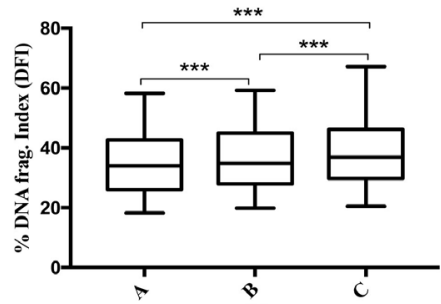

(b)

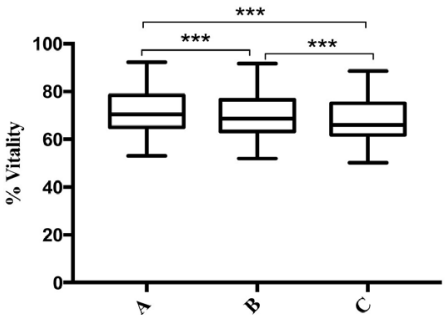

(d)

Figure 1. Pairwise comparisons of measured outcomes across three treatment groups, $\mathrm{A}$ $=$ neat semen sample, $\mathrm{B}=37^{\circ} \mathrm{C}$ incubation, $\mathrm{C}=\mathrm{RF}$-EMW exposed sample, ${ }^{* * *}=\mathrm{p}<$ $0.0001, \mathrm{SOD}=$ superoxide dismutase.

Table 2. Correlation between SOD, DFI and measured semen parameters.

\begin{tabular}{|c|c|c|c|c|c|c|}
\hline & \multicolumn{6}{|c|}{ r values } \\
\hline & \multicolumn{2}{|c|}{ Neat Sample } & \multicolumn{2}{|c|}{ RF-EMW Exposed } & \multicolumn{2}{|c|}{ Un-Exposed } \\
\hline & $\mathrm{SOD}(\mathrm{U} / \mathrm{ml})$ & DFI (\%) & $\mathrm{SOD}(\mathrm{U} / \mathrm{ml})$ & DFI (\%) & $\operatorname{SOD}(\mathrm{U} / \mathrm{ml})$ & DFI (\%) \\
\hline Age & 0.062 & -0.082 & 0.043 & 0.155 & 0.07 & -0.078 \\
\hline $\mathrm{pH}$ & -0.044 & -0.021 & -0.207 & 0.006 & -0.227 & 0.184 \\
\hline Sperm Count & 0.227 & -0.198 & & & & \\
\hline$\%$ Progressive & $0.439^{\star * *}$ & $-0.434^{* *}$ & $0.451^{\star * *}$ & $-0.258^{\star}$ & $0.407^{\star * *}$ & $-0.43^{\star * *}$ \\
\hline$\%$ Non-progressive & $0.578^{\star * *}$ & $-0.559^{* * *}$ & $0.544^{* * *}$ & -0.066 & $0.615^{* * *}$ & $-0.556^{\star * *}$ \\
\hline$\%$ Total Motility & $0.724^{\star * *}$ & $-0.707^{\star * *}$ & $0.705^{\star \star *}$ & $-0.233^{\star}$ & $0.711^{\star * *}$ & $-0.695^{\star * *}$ \\
\hline$\%$ Immotility & $-0.724^{\star * *}$ & $0.707^{\star * *}$ & $-0.705^{\star *}$ & $0.233^{\star}$ & $-0.711^{\star * *}$ & $0.695^{* * *}$ \\
\hline \% Morphology & $0.578^{* * *}$ & $-0.528^{\star * *}$ & & & & \\
\hline$\%$ Vitality & 0.003 & 0.043 & $0.725^{\star * *}$ & -0.178 & $0.728^{* * *}$ & $-0.697^{\star * *}$ \\
\hline SOD & & $-0.90^{* * *}$ & & $-0.270^{*}$ & & $-0.885^{\star \star \star}$ \\
\hline
\end{tabular}

SOD: superoxide dismutase; $\mathrm{r}=$ correlation coefficient; ${ }^{\star}=\mathrm{p}<0.05 ;{ }^{* *}=\mathrm{p}<0.01 ;{ }^{\star * *}=\mathrm{p}<0.0001$. 


\section{Discussion}

The production of reactive oxygen species (ROS) is a normal physiological process in spermatogenesis and ejaculated semen but the state of stress is neutralized by antioxidant enzyme systems present in semen [13] [15]. However, when the increased ROS production overrides the antioxidants neutralizing capacity, it results in a state of oxidative stress with concomitant impact on spermatozoa motility and DNA integrity.

In this study the capacity of semen antioxidant-superoxide dismutase to protect spermatozoa from the damaging effects of RF-EMW emitted from a mobile phone was assessed. Spermatozoa total motility, viability and SOD were significantly reduced with corresponding increase in DNA fragmentation after exposure to RF-EMW radiation compared to unexposed control incubated at $35^{\circ} \mathrm{C}$ (Figure 1). This is indicative that electromagnetic waves emitted from cellular phones can increase ROS formation causing a "heightened" oxidative stress to spermatozoa in ejaculated semen than when compared to internal/self-control not exposed to cellular phone radiation. The significantly reduced spermatozoa motility and viability in exposed semen can be attributed to the higher state of oxidative stress resulting from cellular phone radiation. Increased free radical formation resulting from RF-EMW exposure will cause a higher rate of redox reaction in the spermatozoa's plasma membrane and or on leucocytes present in the semen by stimulating plasma membrane NADH oxidase [16] [17]. The reduced levels of SOD in the exposed group is indicative of a spent antioxidant system trying to mop up the free radicals produced due to RF-EMW exposure (Figure 1).

The human spermatozoa possess multiple plasma membrane redox systems including the trans membrane NADH oxidase activity [18]. Disturbance in free radical metabolism or induction of oxidative stress by cell phone radiation has been demonstrated in some animal studies showing decreased total antioxidant capacity, i.e., reduced catalase, SOD and glutathione peroxidase activity [19] [20] [21].

SOD correlated positively with spermatozoa total motility and viability but negatively with spermatozoa immotility and DFI (Table 2). This could be attributed to the ability of the antioxidant SOD to protect spermatozoa in ejaculated semen from the impact of radiation emitted from cellular phones. Meaning, once SOD levels were high in ejaculated semen, DNA fragmentation induced by free radicals was kept in check and sperm parameters, i.e., motility and viability were not affected but high levels of RF-EMW-induced free radicals causes a swift decline in SOD levels (Figure 1). DFI directly correlated with spermatozoa immotility but inversely with total motility and viability as has been previously reported [16].

Another finding of this study was a significantly reduced SOD levels after incubation at $35^{\circ} \mathrm{C}$ (Un-exposed Controls) (Figure 1(a)) compared to pre-exposure (neat sample). This we attribute to SOD mopping-up or neutralizing the physio- 
logically produced free radicals. Our results are consistent with an in-vitro study by [22]. Esfandiari et al. (2002) [22] who observed significantly increased levels of ROS in semen incubated at $37^{\circ} \mathrm{C}$.

Progressive motility, total motility and viability directly correlated with SOD levels significantly (Table 2). A reduction in sperm motility and viability is associated with increased concentration of superoxide anion in semen. Increased production of superoxide anion in extracellular compartments can oxidize membrane phospholipids [23] causing cell death and the resulting reduction in spermatozoa viability and motility observed.

Sperm production happen at temperatures lower than the normal body temperature of $37^{\circ} \mathrm{C}$ and the effects of elevated temperature on in-vivo and ejaculated sperm motility and viability has been documented [22]. Similarly, we report a reduced sperm motility and viability when aliquots of the ejaculated semen were incubated at $35^{\circ} \mathrm{C}$ after 3 hours. When sperms are incubated at $35^{\circ} \mathrm{C}$, initially there is an increase in the rate and fraction of motile sperms, however, with time the rate and proportion of motile sperms decline possibly due to sperm exhaustion and ATP depletion [24] [25] and we speculate this to be the reason for our observation.

Studies regarding sperm DNA damage are complicated due to variations in methodology and interpretations. In this study there was RF-EMW-induced DNA damage as depicted by the increased DFI after RF-EMW exposure (Figure 1(b)). Our findings corroborate an in-vitro study by [26] on human ejaculated semen. Aitken et al. [27] reported that mice exposed to RF-EMW, $900 \mathrm{MHz}, 12$ hours/day for 7 days led to damage to the mitochondrial genome and nuclear beta-globin locus of epididymis spermatozoa. Spermatozoa are extremely vulnerable to DNA damage as they lose their cytoplasm which contains antioxidant enzymes during spermatogenesis [27] and thus exposure to radiation may easily damage the DNA. This is the probable explanation for the high DFI observed after exposure to the radiation (Figure 1(b)).

Direct extrapolation based on our study results about the effects of RF-EMW emitted from cell phones kept in pants on sperm quality should be made cautiously considering that this study sought to create an in-vitro simulation model and this may not happen physiologically.

\section{Conclusion}

A high level of seminal SOD is protective against the effects of cellular phones electromagnetic waves-induced oxidative stress on sperm parameters. Continuous exposure to RF-EMW can lead to a significant reduction in seminal SOD concentrations. Although this research was carefully prepared, we were still aware of its limitations and shortcomings. Based on the outcome of this research through in-vitro, we would recommend that an in-vivo model using Laboratory mice or rats be performed and the results compare after the necessary ethical clearance have been approved. 


\section{Authors' Contributions}

$\mathrm{EB}, \mathrm{CO}$ and RHA conceived and designed the study. EB performed experiments. $\mathrm{EB}, \mathrm{EA}, \mathrm{EAO}$ and $\mathrm{MBY}$ analysed the data. MBY and DM wrote the manuscript. All authors critically reviewed the manuscript.

\section{Conflicts of Interest}

The authors declare no conflicts of interest regarding the publication of this paper.

\section{References}

[1] Butler, P. and Khanna, J. (2003) Assisted Reproduction in Developing Countries Facing Up to the Issues. Progress in Reproductive Health Research. World Health Organization, Geneva.

[2] Vayena, E., Rowe, P.J. and Peterson, H.B. (2002) Assisted Reproductive Technology in Developing Countries: Why Should We Care? Fertility and Sterility, 1, 13-15. https://doi.org/10.1016/S0015-0282(02)03177-1

[3] Irvine, N. (2010) Definition, Epidemiology and Management of Electrical Sensitivity. Report of the Radiation Protection Division of the Health Protection Agency, Ireland.

[4] Rowe, P.J. and Comhaire, F.H. (2010) WHO Manual for the Standardized Investigation and Diagnosis of the Infertile Male. Cambridge University Press, Cambridge.

[5] Wdowiak, A., Bakalczuk, S. and Bakalczuk, G. (2015) Decreased Activity of Superoxide Dismutase in the Seminal Plasma of Infertile Men Correlates with Increased Sperm Deoxyribonucleic Acid Fragmentation during the First Hours after Sperm Donation. Andrology, 4, 748-755. https://doi.org/10.1111/andr.12061

[6] Hosoki, A., Yonekura, S., Zhao, Q.L., Wei, Z.L., Takasaki, I., Tabuchi, Y. and Zhang-Akiyama, Q.M. (2012) Mitochondria-Targeted Superoxide Dismutase (SOD2) Regulates Radiation Resistance and Radiation Stress Response in HeLa Cells. Journal of Radiation Research, 1, 58-71. https://doi.org/10.1269/jrr.11034

[7] Carpenter, D.O. (2013) Human Disease Resulting from Exposure to Electromagnetic Fields. Reviews on Environmental Health, 4, 159-172. https://doi.org/10.1515/reveh-2013-0016

[8] Akanlisikum, A., Aziale, L.K. and Asampana, I. (2014) An Empirical Study on Mobile Phone Usage among Young Adults in Ghana: From the Viewpoint of University Students. Children, 13, 33.

[9] Mahan, A.K., Melody, W.H. and Frempong, G. (2009) Mobile Telephone Opportunities: The Case of Micro- and Small Enterprises in Ghana. Information, 2, 79-94. https://doi.org/10.1108/14636690910941902

[10] Huber, R., Graf, T., Cote, K.A., Wittmann, L., Gallmann, E., Matter, D. and Achermann, P. (2000) Exposure to Pulsed High-Frequency Electromagnetic Field during Waking Affects Human Sheep EEG. Neuroreport, 15, 3321-3325. https://doi.org/10.1097/00001756-200010200-00012

[11] Oftedal, G., Wilen, J., Sandstrom, M. and Mild, K.H. (2000) Symptoms Experienced in Connection with Mobile Phone Use. Occupational Medicine, 4, 237-245. https://doi.org/10.1093/occmed/50.4.237

[12] Preece, A.W., Iwi, G., Davies-Smith, A., Wesnes, K., Butler, S., Lim, E. and Varey, A. (2018) Effect of a 915-MHz Simulated Mobile Phone Signal on Cognitive Func- 
tion in Man. International Journal of Radiation Biology, 4, 447-456. https://doi.org/10.1080/095530099140375

[13] Agarwal, A., Makker, K. and Sharma, R. (2008) Review Article: Clinical Relevance of Oxidative Stress in Male Factor Infertility: An Update. American Journal of Reproductive Immunology, 1, 2-11. https://doi.org/10.1111/j.1600-0897.2007.00559.x

[14] World Health Organisation (2010) WHO Laboratory Manual for the Examination and Processing of Human Semen. 5th Edition.

[15] Sharma, R.K., Pasqualotto, F.F., Nelson, D.R., Thomas, A.J. and Agarwal, A. (2008) The Reactive Oxygen Species-Total Antioxidant Capacity Score Is a New Measure of Oxidative Stress to Predict Male Infertility. Human Reproduction, 11, 2801-2807. https://doi.org/10.1093/humrep/14.11.2801

[16] Agarwal, A., Desai, N.R., Makker, K., Varghese, A., Mouradi, R., Sabanegh, E. and Sharma, R. (2009) Effects of Radiofrequency Electromagnetic Waves (RF-EMW) from Cellular Phones on Human Ejaculated Semen: An in Vitro Pilot Study. Fertility and Sterility, 4, 1318-1325. https://doi.org/10.1016/j.fertnstert.2008.08.022

[17] Friedman, J., Kraus, S., Hauptman, Y., Schiff, Y. and Seger, R. (2007) Mechanism of Short-Term ERK Activation by Electromagnetic Fields at Mobile Phone Frequencies. Biochemical Journal, 3, 559-568. https://doi.org/10.1042/BJ20061653

[18] Aitken, R., Ryan, A., Curry, B. and Baker, M. (2003) Multiple Forms of Redox Activity in Populations of Human Spermatozoa. Molecular Human Reproduction, 11, 645-661. https://doi.org/10.1093/molehr/gag086

[19] Meral, I., Mert, H., Mert, N., Deger, Y., Yoruk, I., Yetkin, A. and Keskin, S. (2007) Effects of 900-MHz Electromagnetic Field Emitted from Cellular Phone on Brain Oxidative Stress and Some Vitamin Levels of Guinea Pigs. Brain Research, 1169, 120-124. https://doi.org/10.1016/j.brainres.2007.07.015

[20] Ozguner, M., Koyu, A., Cesur, G., Ural, M., Ozguner, F., Gokcimen, A. and Delibas, N. (2007) Biological and Morphological Effects on the Reproductive Organ of Rats after Exposure to Electromagnetic Field. Saudi Medical Journal, 3, 405-410.

[21] Irmak, M.K., Fadıllıŏlu, E., Güleç, M., Erdoğan, H., Yağmurca, M. and Akyol, Ö. (2014) Effects of Electromagnetic Radiation from a Cellular Telephone on the Oxidant and Antioxidant Levels in Rabbits. Cell Biochemistry and Function, 4, 279-283. https://doi.org/10.1002/cbf.976

[22] Esfandiari, N., Saleh, R.A., Blaut, A.P., Sharma, R.K., Nelson, D.R., Thomas, A.J. and Agarwal, A. (2002) Effects of Temperature on Sperm Motion Characteristics and Reactive Oxygen Species. International Journal of Fertility and Women's Medicine, 5, 227-235. https://doi.org/10.5534/wjmh.2014.32.1.1

[23] Henkel, R., Kierspel, E., Stalf, T., Mehnert, C., Menkveld, R., Tinneberg, H.R. and Kruger, T.F. (2005) Effect of Reactive Oxygen Species Produced by Spermatozoa and Leukocytes on Sperm Functions in Non Leukocytospermic Patients. Fertility and Sterility, 3, 635-642. https://doi.org/10.1016/j.fertnstert.2004.11.022

[24] De Lamirande, E. and Gagnon, C. (1991) Reactive Oxygen Species and Human Spermatozoa. Depletion of Adenosine Triphosphate Plays an Important Role in the Inhibition of Sperm Motility. Journal of Andrology, 5, 379-386.

[25] De Lamirande, E. and Gagnon, C. (1992) Reactive Oxygen Species and Human Spermatozoa: Effects on the Motility of Intact Spermatozoa and on Sperm Axonemes. Journal of Andrology, 13, 368-368.

[26] Veerachari, S.B. and Vasan, S. (2012) Mobile Phone Electromagnetic Waves and Its Effect on Human Ejaculated Semen: An in Vitro Study. International Journal of Infertility and Fetal Medicine, 1, 15-21. 
https://doi.org/10.5005/jp-journals-10016-1034

[27] Aitken, R., Bennetts, L., Sawyer, D., Wiklendt, A. and King, B. (2005) Impact of Radio Frequency Electromagnetic Radiation on DNA Integrity in the Male Germline. International Journal of Andrology, 3, 171-179.

https://doi.org/10.1111/j.1365-2605.2005.00531.x 